Leonardo A. Santamaría Delgado*

\title{
El urbanismo colonial en la ciudad de Tunja ${ }^{1}$
}

\author{
The colonial urbanism in the city of Tunja
}

Cómo citar:

Santamaría, L. A. (2017). El urbanismo colonial en la ciudad de Tunja. Designia, 4(2), 61-81.

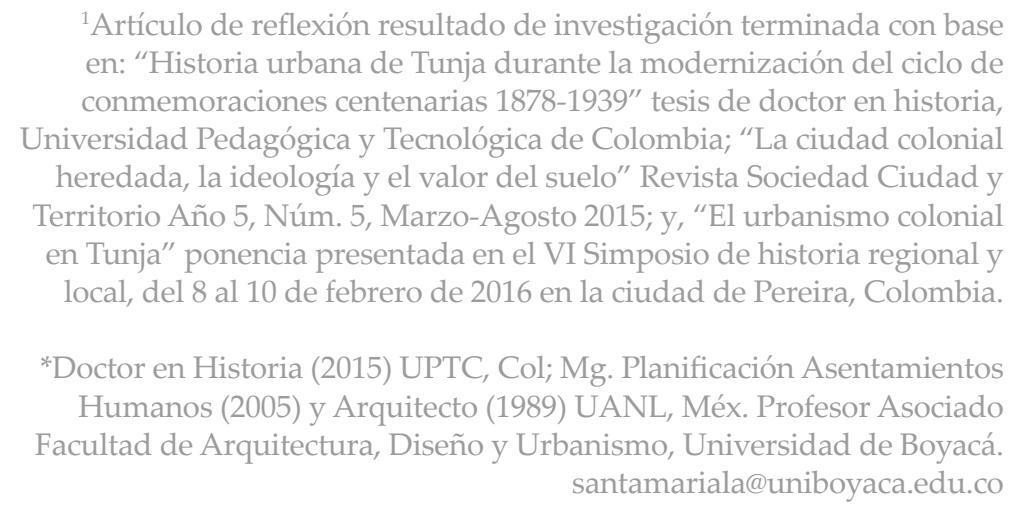

Palabras clave:

Urbanismo, Ciudad, Tunja, morfología, Policía, Religión.

Key words:

Urbanism, City, Tunja,

Morphology, Police, Religion.

Recibido: 08/11/2016

Aceptado: 11/02/2017

santamariala@uniboyaca.edu.co

Resumen:

El artículo gira en torno al sustento ideológico del urbanismo colonial hispano que se implanta al fundar la ciudad de Tunja sobre el asentamiento Muisca ubicado en la cordillera oriental de los Andes, basado en una clasificación y diferenciación social entre las razas blanca e indígena que reproduce el sueño de un orden normado por la metrópoli y se expresa en la morfología que adopta la ciudad mediante un sistema procesional parroquial que rige toda actividad local, y por el cotidiano sometimiento que autoridades civiles y religiosas ejercen sobre sí y sobre los naturales mediante el poder de policía y de la religión, concluyendo que, existe una división social del espacio urbano evidente en la división parroquial que se prolonga al presente. 


\section{Abstract:}

The article revolves around the ideological support of Hispanic colonial urbanism that is implanted when founding the city of Tunja on the settlement Muisca located in the eastern range of the Andes, based on a classification and social differentiation between the white and indigenous races that reproduces the dream of an order regulated by the metropolis and is expressed in the morphology that the city adopts through a parochial processional system that governs all local activity, and by the daily subjugation that civil and religious authorities exert over themselves and over the natives through the power of police and religion, concluding that there is a social division of urban space evident in the parochial division that continues to the present.

\section{INTRODUCCIÓN}

Este artículo integra varias perspectivas de análisis formuladas por estudiosos del origen de la ciudad colonial, reinterpretadas y articuladas dentro de una reflexión acerca del urbanismo en Tunja, ejemplo clásico de fundación española que se extendió a lo largo de tres siglos, desde el asentamiento sobre territorio Muisca hasta la guerra de independencia. Se cuenta con un soporte gráfico consistente en croquis de trazas y planos de 1623 y 1816. El cuerpo del análisis se estructura con el texto de Jaime Salcedo Urbanismo Hispanoamericano, siglos XVI, XVII y XVIII, que estudia la génesis y el desarrollo del modelo urbano aplicado en Hispanoamérica, al cual se atribuyen orígenes vinculados con la religión profesada por los Reyes Católicos. Asimismo, se tienen en cuenta planteamientos de autores como Beltrán de Heredia, Bonet Correa, Carías, Morse y Rojas Mix.

Sin embargo, estos autores no desarrollaron el concepto de policía urbana dentro del análisis de la ciudad, tal como lo hace Suárez García en el artículo El urbanismo humanista y la policía española en el Nuevo Reino de Granada, siglo XVI, al plantear que el modelo de dominación del proyecto humanista evangelizador católico para la conversión de los nuevos paganos era complementario al de "vivir en policía".

En Tunja, el ensayo temprano Tunja y sus vecinos, escrito por Cortes Alonso, concluye la existencia de una división social del espacio basada en preeminencias sociales. Los pobladores de raza blanca ocupaban el primer cuadro de la traza, en tanto los mestizos e indios ocupaban el ensanche urbano, tal como lo expresan los estudios de la ciudad colonial de Colmenares y Wiesner. 
Por último, el sentido simbólico de Tunja se aborda a través del estudio Crónica colonial de Tunja y su provincia, de Porras Collantes, que examina como el tiempo y el espacio ordinarios de la ciudad profana se transforman en otros de tipo litúrgico en la ciudad sagrada por medio de la espectacularidad de recorridos procesionales sobre vías sacras, en refuerzo del cotidiano adoctrinamiento del culto católico. Sobre este particular también se considera a Mejía Pavony, a Rojas y a Dorta.

\section{EL URBANISMO EN LA CIUDAD DE TUNJA DURANTE LA ÉPOCA COLONIAL}

La colonización de América por España, Portugal, Francia, Inglaterra, Dinamarca y Holanda entre los siglos XVI y XVII funda las primeras ciudades, siguiendo modelos diversos. España sigue un modelo regular en los virreinatos de Nueva España, Nueva Granada, Perú y Río La Plata, un urbanismo hispanoamericano inscrito en tres periodos de acuerdo con los proyectos Colombino, Ovandino y Filipino.

El proyecto Colombino inicia en 1492 con las capitulaciones de Santa Fe que firman los Reyes Católicos y Cristóbal Colón, y termina en 1500 con la rebelión de La Española. Es una empresa monopólica para establecer factorías en ciudades concebidas como enclaves comerciales, con población a su servicio y funciones de exacción económica, producción alimentaria, navegación y defensa militar, pero destinada al fracaso por no ser tradición castellana, que culmina transformando los empleados en colonos al repartir tierras de La Española (Salcedo Salcedo, 1996).

El proyecto Ovandino, tras superar la crisis de Nuevas Leyes de 1542, se prolonga hasta 1573 para hacer de la factoría una colonia con sistema social, económico y político extensivo hacia Hispanoamérica. Funda ciudades y villas gobernadas por cabildos y alcaldes, reparte tierras y solares urbanos para hacerlos productivos y vivir, busca oro pagando tributo a la Corona, puebla con familias de España o indígenas en plazo de tres años y ve en la encomienda una política de colonización ${ }^{2}$.

La Provisión Real de 1503, al definir a los indios libres no sujetos a servidumbre, los concentra en pueblos como vasallos de la Corona y no siervos, según la Instrucción de 1503. Quedan sujetos al régimen de vida urbano por instrumentos jurídicos de dominio y gobierno civil, tales como las Cédulas de 1503 sobre control comercial, naviero y migratorio; de 1507 de alcaldes; de 1523 y 1568 de cabildos; y de 1538 de encomenderos, que fija su residencia en casas de piedra, argamasa o tapiería.

El proyecto Ovandino establece la ciudad indiana por cruce de calles rectas a

${ }^{2}$ Frey de Ovando los implanta en Nueva España, Nueva Granada, Perú y Río La Plata. partir de la plaza mayor cerca al puerto, con iglesia orientada y exenta sin fachada a la plaza, ayuntamiento en la plaza mayor y manzanas cuadradas o rectangulares. Es el asiento solariego de vecinos y pobladores que replican las primeras generaciones 
de conquistadores fundadores de ciudades hasta la proclamación de las Nuevas Leyes de 1542, revocadas tras los disturbios entre encomenderos que amenazan la integridad del sistema colonial (Salcedo Salcedo, 1996).

Al proyecto Filipino (1573 al siglo XVIII), lo rigen Ordenanzas de Poblaciones promulgadas por Felipe II para desmontar el régimen de encomienda y ordenar que sobre la plaza los solares no se destinen a particulares sino a la iglesia, las tiendas, las casas reales y de tratantes, mientras que los demás han de repartirse por suerte entre la población. También innova el diseño de plaza en cuadro prolongado, del que salen por mitad de los costados cuatro calles y ocho más por las esquinas, en contra del orden tradicional de la milicia alrededor de una plaza rectangular ${ }^{3}$.

El proyecto de Carlos III sobre nuevas poblaciones del siglo XVIII forma el nuevo modelo colonizador en regiones fronterizas al abolir la mayoría de encomiendas en 1720 y expulsar a los jesuitas en 1767. Esto deja vastas regiones en abandono como centros de resistencia indígena, por ello, las villas de frontera conservan tradiciones de poblamiento del siglo XVI pero no se basan en la encomienda ni en la preeminencia del poblador, sino en el valor de la tierra al recompensar labradores y soldados, en tanto las calles de la traza incorporan árboles contra el ardor del sol.

Las normas europeas implantadas en América primero catalizan en ciudad fuerte para conquista del territorio, asentamiento de avanzada, punto de enlace y llegada de galeones metropolitanos. Asimismo, en ciudad puerto amurallada con funciones mercantiles, militares y administrativas, que es hostilizada por indígenas, corsarios y piratas, como San Juan de Puerto Rico, Santiago de Cuba o Cartagena de Indias.

Otras ciudades (como Puebla entre el puerto de Veracruz y la Ciudad de México) son punto de paso entre ciudades indígenas, una escala segura de recorridos hacia los tesoros. Asunción del Paraguay reagrupa personas y mercancías que se encaminan a la región minera, hacia fundaciones de cordillera (Jujuy, Salta, Catamarca, Rioja,

${ }^{3}$ Se aplica en tipos urbanos de los siglos XVII y XVIII, a cargo de los jesuitas desde 1566 (Leyes de los Reynos de Indias, Madrid, 1791, Tomo 2, Libro IIII, Títulos 7 y 8. Disponibles en http://www congreso.gob.pe/ntley/ LeyIndiaP.htm). San Juan y Mendoza), o jalona caminos a Perú y río La Plata por Tucumán, Santiago del Estero y Córdoba (Salcedo Salcedo, 1996).

Las más populosas se levantan sobre ciudades indígenas con poder político, como México, Cuzco, Cholula, Bogotá, Tunja, Quito, Huamanga, Chiquisaca, Mendoza o San Pablo Brasil, incorporadas y ordenadas al nuevo sistema colonial. Igualmente, resultan de misiones y reducciones indígenas de órdenes religiosas, o son poblados mineros, como ocurre con Popayán en Colombia, Guanajuato y Taxco en México, Villa Rica (actual Ouro Preto en Brasil) y Potosí en Bolivia (Romero, 1999). 
El damero con plaza fue símbolo y vehículo del avance imperial desde tres teorías político-religiosas: la humanista o misión civilizadora; la mesiánica o cristianización de Indias por el Antiguo Testamento; y la dominicana aristotélica tomista o de comunidad de naciones del derecho de gentes romano. Todas son resistidas por encomiendas que se conciben como polis agrourbanas semiautónomas, en conflicto con el orden privado del sistema patriarcal jerárquico -sobrepuesto al religioso indígena de grupos tribales con lazos de parentesco- similar al campamento romano pero bajo consideraciones estratégicas, políticas y agrícolas no comerciales o industriales, repartido según jerarquías sociales y militares propias (Morse, 1975).

La ciudad colonial representa el cosmos cristiano universal ordenado desde una plaza, donde el rollo o picota se erige como centro del mundo, símbolo fundacional por excelencia y sitio donde el Justicia Real hace efectivo su poder sobre la vida o la muerte, da recompensa o castigo ante todo vasallo. El centro es el asiento de una aristocracia de origen militar, el mejor sitio para vivir de la nobleza feudal. El modelo de la ciudad indiana es el del ordenamiento cósmico cristiano, donde el mundo indígena es considerado el caos primordial (Morse, 1975).

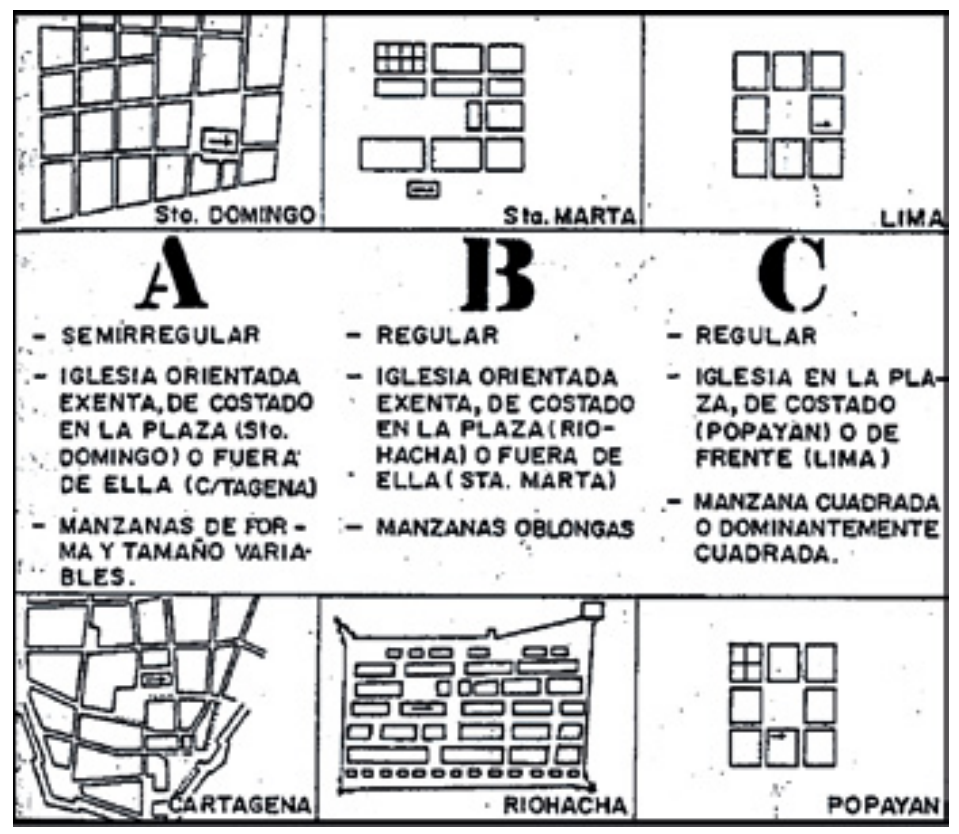

Figura 1. Tipos de trazas. Fuente: Salcedo Salcedo (1996, p. 43). 
Los trazos típicos en la América española son tres: el semirregular (Santo Domingo y Cartagena); el regular de manzana oblonga (Santa Marta o Riohacha); y el regular de manzana cuadrada (Lima o Popayán). Los dos primeros tienen origen en la tradición medieval española de castrametación, codificada por Alfonso $X$, de traza regular con manzana alargada, en tanto el último, en la ciudad ideal de Eiximenic, de traza ortogonal, manzana cuadrada e iglesia mayor separada de la plaza, elementos que se combinan en cada fundación (Salcedo Salcedo, 1996).

El modelo de colonización española se basó en dos trazas: la de tradición militar asociada con el campamento romano, que reconoce las manzanas alargadas, y la de tradición cristiana de ciudad ideal, forjada en España durante la Edad Media, con manzana cuadrada. Ambas redujeron el modelo teórico de ciudad indiana a otro de inspiración divina: la Nueva Jerusalén ${ }^{4}$ (Beltrán de Heredia, 1982) que representa la Jerusalén Celestial del Apocalipsis y las visiones del profeta Ezequiel, e influye en las Ordenanzas Filipinas de 1573 (Salcedo Salcedo, 1996).

La plaza mayor tiene un significado de corazón de la ciudad, núcleo generador de una traza diseñada idealmente a priori que se transforma en algo propio de América. Es el punto cero de la intersección entre caminos, sede de las instituciones, lugar de celebración y de convergencia comunitaria cotidiana, síntesis del macrocosmos representado por barrios o cuarteles escalonados, articulados con el microcosmos de viviendas con patio central (equivalente a la plaza) donde transcurre la vida íntima y familiar. Es un modelo contrario al de España y Europa, donde la plaza es una operación urbanística a posteriori del tejido urbano (Bonet Correa, 1991). Así, por ejemplo, en la figura 2 se aprecian diferentes etapas en la conformación de la plaza de Popayán y sus espacios circundantes: 1) se delimita la plaza y se ubica el rollo; 2) se asignan los solares de la iglesia y el cabildo; 3) se adjudican solares para los fundadores en el marco de la plaza; 4) los restantes se entregan a capitanes destacados; 5) se asignan aquellos que dan a las calles que entran a la plaza; 6) se adjudican los destinados a los conventos.

\footnotetext{
${ }^{4} \mathrm{La}$ "ciudad perfecta

humanística" (siglo XIV), del franciscano catalán Francesc Eiximenic, con su cuadrado de dos ejes perpendiculares sobre la plaza mayor, se remonta al Antiguo Testamento.
} 


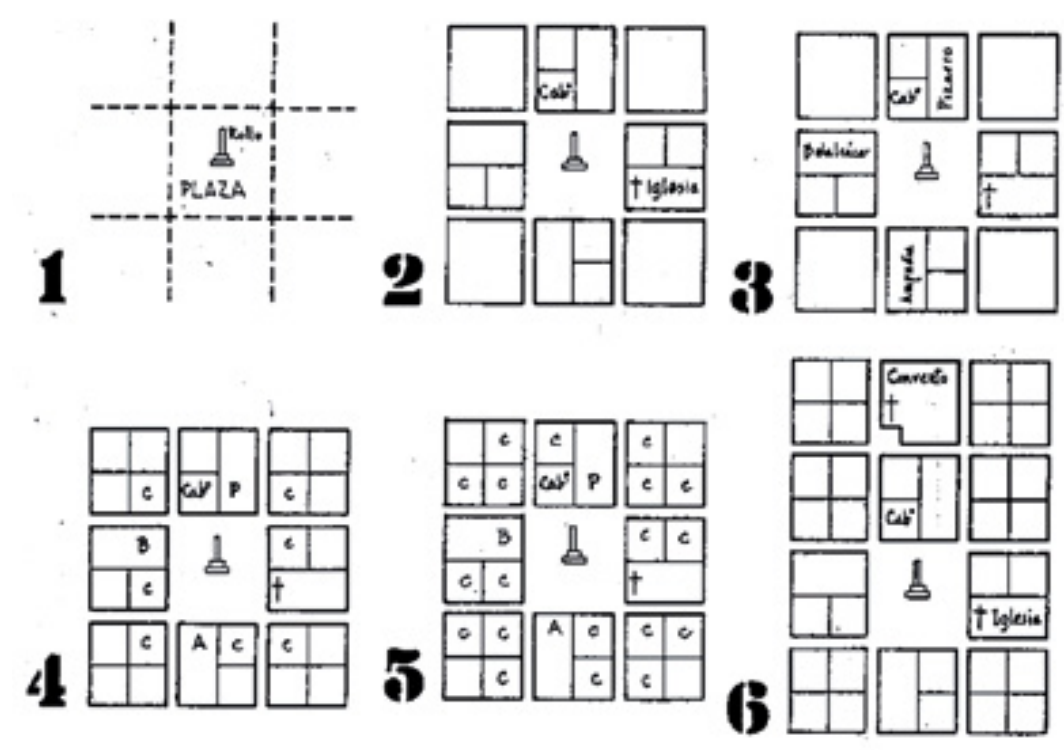

Figura 2. Trazo de Popayán.

Fuente: Salcedo Salcedo (1996, p. 53).

\footnotetext{
${ }^{5}$ Con fueros locales y

municipios libres, preburgués e individualista, subordina el servicio público a la unidad social corporativa, ajena al absolutismo y la mentalidad feudal.
}

La plaza mayor refleja la sociedad que España trasplanta en América. Lugar de encuentro, intercambio social y gobierno municipal, de presión moral y religiosa para los naturales, quienes perciben a quien domina. Allí se participa de ver o de ser visto, algo propio de América y contrario a los burgos del viejo conteniente, donde abrir una plaza significa romper la urdimbre medieval. Rojas Mix (1978) cita que Ortega y Gasset opinaba que el español no era del tipo mediterráneo sino un hombre de plaza mayor, del corazón de la ciudad, un ser social acosado que vive rodeado y vigilado por los demás, desde su nacimiento hasta su muerte.

El origen de la urbe colonial se basa en la tensión entre polis o ciudad del hombre y ciudad universal de Dios, con clave en la obra de Santo Tomás de Aquino, De regimine principium, que reconcilia la vida cívica y los intereses de comunidad política de Aristóteles con los de salvación personal y las virtudes propias de la ciudad cristiana de San Agustín 5 . En ambas ciudades, hermanadas por la industria, el individualismo cede al servicio público y la unidad social corporativa, con un sistema de intercambio ordenado de bienes. Esta visión influye en tratadistas españoles medievales, tales como Francesc Eiximenic y el obispo Rodrigo Sánchez de Arévalo, al igual que en las ordenanzas de Indias (Morse, 1975). 
La eficacia del damero en la labor misional de dominación ideológica se resume en que la plaza cumple una función de organismo regulador de relaciones entre colonizadores (grupo social privilegiado) y colonizados (indígenas encomendados), sometidos a pautas de incorporación en la sociedad como mano de obra tributaria, quienes forman un núcleo poblacional para explotación de las regiones circundantes al servicio del grupo dominante venido de España (Rojas Mix, 1978).

Desde el punto de vista religioso, la ideología que orienta la acción de los grupos dominantes en el proceso de conquista y colonización se expresa en la "idea de la gracia", defendida por el catolicismo español, según la cual, "Dios" capacita la voluntad humana para ejecutar su voluntad dentro de la iglesia universal. De tal modo, se configura una visión del mundo, una relación de comunidad entre fieles y gentiles con centro en la plaza ${ }^{6}$. Esta se adecúa con funciones políticas, económicas y sociales del mercantilismo español, junto a otras del catolicismo para convertir los indígenas a la religión, con fundamento en el descubrimiento (Rojas Mix, 1978).

bajo la "idea de la gracia" separa entre hombres buenos y malos, blancos y de color,

elegidos y condenados, como lo hace el colonizador puritano de la América anglosajona, a quien el don de la gracia le convierte en "elegido" y reproduce la "comunidad divina" en la colonia.
${ }^{7}$ Las funciones político-ideológicas asignadas a la plaza en la ciudad colonial-misional son: compeler al indígena a vivir de manera política y cristiana, ejercer control político y sofocar sublevaciones.

${ }^{8}$ Referidas a las disposiciones que procuran regular los derechos entre españoles e indígenas.
El catolicismo español encuentra concordancia entre la predestinación del hombre y la gracia de Dios en la doctrina del libre albedrío y la acción eclesiástica destinada a ayudar en la salvación a través de los sacramentos como acción civilizadora. Así, posibilita el control, la obediencia y subordinación en un ejercicio de dominación política entre la Iglesia y el Estado, en una estructura de ciudad abierta con apertura institucional a todo hombre, sin barreras de acceso. A su vez, congrega a la comunidad sometida alrededor del centro ${ }^{7}$ para adoctrinarla, en una tarea cotidiana de remodelación ideológica de amor a Dios y al monarca (Rojas Mix, 1978).

Por el carácter evangélico de la conquista y sus instrucciones ${ }^{8}$ lo primero que se edifica es la iglesia. Debido a que desde las Constituciones Apostólicas del siglo V al sacerdote estaba obligado a volverse hacia el oriente para realizar la consagración, de espaldas a la asamblea, la iglesia debe construirse hacia el este de la plaza, con fachada de entrada al oeste y bóveda semicircular que sobresale en la fachada posterior o ábside al oriente. Además, se prescribe que a cada cierta distancia sobre la trama es preciso dejar plazas menores para edificar los templos parroquiales y monasterios dependientes de la iglesia mayor, en aras de un reparto apropiado de la doctrina entre igual número de vecinos (Brewer Carías, 1998).

La traza regular con manzana cuadrada denominada traza limeña es difundida por el antiguo Virreinato del Perú al fundar Lima con la plaza mayor y el rollo o picota hacia las fachadas de las casas del cabildo, soportales del comercio, y la iglesia en la esquina de la cuadra del levante, tal como en Tunja, Pamplona y Bogotá. Esta traza 
difiere de la quiteña, cuya iglesia tiene fachada sobre una calle lateral y una puerta falsa o puerta del perdón da a la plaza (tal es el caso en Quito, Cali, Popayán, Cartago, Buga y Pasto). Hay otras variaciones en geometría, subdivisión de solares y ubicación de la iglesia, como la traza chilena, alto peruana, santafesina, jujeña, tucumana y aquellas sobre ciudades prehispánicas (Salcedo Salcedo, 1996).

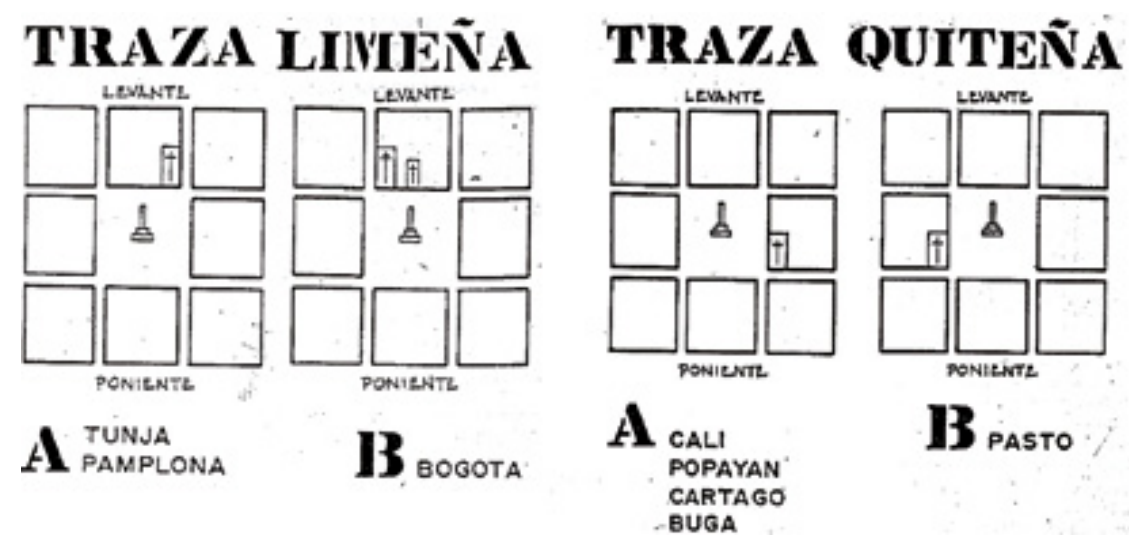

Figura 3. Trazas urbanas difundidas.en el virreinato de Perú Fuente: Salcedo Salcedo (1996, p. 68)

Después de repartidos los solares, los términos y el territorio agrícola (que se extienden a cuatro leguas) se reparten entre escuderos y peones, sin exceder tres caballerías o cinco peonías en ningún caso. La caballería equivale a dos peonías y estas son solares de 50 pies de ancho y 100 de largo, con cultivos de cereales, árboles y ganado, que están exentos de pagar almojarifazgos y alcabalas. Además, los ejidos forman el resguardo indígena encomendado y las dehesas se reparten entre propios, el fundador y los pobladores (Salcedo Salcedo, 1996).

La genealogía de formas urbanas muestra una estrecha relación entre la morfología de la ciudad, la moral y los comportamientos como prácticas de buen gobierno desarrolladas por España desde el siglo XIII mediante la policía urbana. Se pretende fomentar el cuidado, regular el orden, los comportamientos y la forma de la ciudad. Una "vida en policía" apunta a homogenizar la cultura a través de un acuerdo entre los Reyes Católicos y el clero para imponer un orden que erradique el antiguo sistema de creencias (cooptado por el cristianismo). La "policía" es considerada una virtud de la fe cristiana opuesta a las prácticas de "idolatría” (Suárez García, 2015). 
La expresión "vivir en policía" define la vida urbana y política, el buen gobierno y la justicia, el correcto orden, la cortesía en el trato y las costumbres, el aseo, la belleza y pulidez que persisten hasta el siglo XVIII. La antinomia "policía" o "barbarie" remite a una virtud de orden y armonía que se opone a la holgazanería. Esta última describe el orden social entre los indígenas, desde quienes viven encomendados y proclives a cambiar sus costumbres hasta los salvajes que permanecen esparcidos. Es una forma de organizar a los paganos y someterlos a la religión católica al vivir en policía sobre un trazo ordenado del territorio (Suárez García, 2015).

9 Según Suarez García (2015), los asentamientos indígenas

Muiscas dependientes del

zacazgo Quemuenchatecha se nuclearon en la provincia de Tunja en estos pueblos: Sora, Cucaita, Samacá, Sáchica, Oicatá, Soracá, Cómbita, Chivatá, Boyacá, Motavita, Ramiriquí, Viracachá, Siachoque, Pesca, Iza, Cuitiva, Tópaga, Gámeza, Busbanza, Socotá, El Cocuy, Soata, Sativa, Duitama y Paipa.
Los Acuerdos de la Real Audiencia de Santafé traducen e interpretan las Cédulas y Ordenanzas Reales del siglo XVI a través del oidor licenciado Tomás López, quien al visitar la provincia de Tunja en 1560 ordena construir iglesias por cuenta de los encomenderos para catequizar a los naturales y expresa la necesidad de apremiar la fundación de "pueblos de indios" para nuclearlos en forma de policía, como ocurre en Santafé y Tunja. Estos pueblos se justifican por obras evangelizadoras como las de Juan de los Barrios y Luis Zapata de Cárdenas, obispos franciscanos del Nuevo Reino de Granada. En su visita a la provincia en 1605, Luis Henríquez consolida un orden territorial alrededor de Tunja al nuclear 24 de ellos9. Suárez García (2015) presenta un plano hipotético de traza en pueblos de indios. En la plaza se encuentran la iglesia, la casa cural, los caciques por repartimientos, los capitanes y particulares. El trazado consta de calles rectas y limpias, mientras que cada manzana tiene callejuelas interiores para la repartición de los solares (Figura 4). 


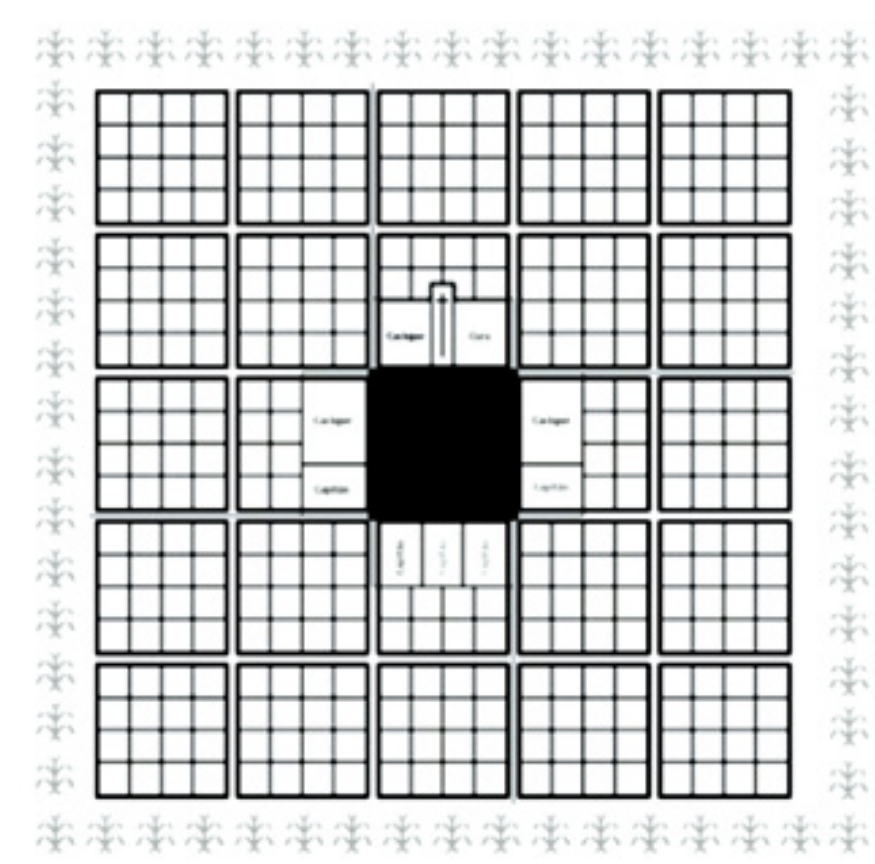

Figura 4. Plano hipotético de traza en pueblos de indios. Fuente: Suárez García (2015, p. 151).

Destaca en la estructura urbanística del proyecto humanista que la ciudad y su área circundante sea la mayor expresión de la civilización occidental como espacio pedagógico y emocional para controlar la población española e indígena. Para tal fin se recurre a prácticas de buen gobierno condensadas en principios de "policía", merced a las características geográficas, socioeconómicas, culturales y ambientales. La clave está en las iglesias, erigidas como el principal factor de poder que da coherencia, orden y ritmo a la ciudad (Mejía Pavony, 2000).

En lengua muisca, 'Tunja' o 'Chunza' significa 'tunjo', 'ídolo' o 'santuario' (Londoño, 1992) Era el reino de los zaques que con los zipas de Bacatá o Muequeta formaron el tercer imperio indígena conquistado por los españoles. Estos, en cabeza de Gonzalo Suárez Rendón, teniente del conquistador Gonzalo Jiménez de Quezada y en presencia del escribano Domingo de Aguirre, fundan el 6 de agosto de 1539 la villa de Tunja sobre el cercado Quemuenchatecha, según los cronistas del siglo XVI.

El carácter señorial de Tunja evidencia la superioridad congénita del hidalgo y acompaña el sistema de convenciones del fundador Suárez Rendón y del escribano del rey Juan de Vargas. Encomenderos y funcionarios acarician ese carácter como actitud oficial, rodeándose de todo lo que recuerde su tierra natal: muebles, utensilios, vestidos, 
vasijas, pinturas, imágenes, casas en adobe, ladrillo y madera, y los aires conventuales de órdenes religiosas (franciscanas, dominicas, carmelitas, agustinas, mercedarias y jesuitas). Es una sociedad barroca homóloga al "sueño de orden" normado desde la metrópoli española (Romero, 1999).

La mentalidad conquistadora y mercantil de Tunja lleva a entenderle como centro de concentración del poder encomendero, jerarquizado por preeminencia social con parentesco señorial a modo de sistema aristocrático que apropia los excedentes indígenas de la economía del suelo (Colmenares, 1970). Sin embargo, en la relación entre poder, apropiación del suelo y estratificación social, al circular entre todos los estamentos en la "ciudad encomendera", el clero es quien concentra las propiedades en capellanías y censos (Wiesner, 2008).

Como la mayoría de fundaciones, el trazo inicial fue de 25 cuadras para solares, con edificios religiosos, administrativos y civiles a partir de la plaza mayor, centro de actividad económica y social de los más pudientes, quienes se ubican a lo largo de plazuelas con fuentes de agua, calles y desagïes a cielo abierto que bajan al arrabal de los menos pudientes. Los edificios religiosos imitan el modelo barroco peninsular para configurar el barroco mestizo: adobe, ladrillo y maderas son recursos disputados por las distintas órdenes religiosas (Romero, 1999).

${ }^{10}$ Con un tamaño de 65 por $80 \mathrm{~cm}$ y hecho a dos tintas sobre cuero de venado. Una fotografía retocada del plano aparece en Porras Collantes (2006).
Aunque el plano de repartición de solares de fundación se desconoce, la Curia Arzobispal de Tunja conserva un plano de $1623^{10}$ que ilustra el pleito sobre la distribución de la feligresía entre las tres parroquias de la ciudad. Cada cuadra tiene dibujadas las casas existentes, con los nombres de sus dueños o habitadores, las iglesias y fuentes de agua. La plaza central está rodeada por la iglesia, las casas reales y las calles (tiradas a cordel) con cuadras y solares (Cortes Alonso, 1985). 


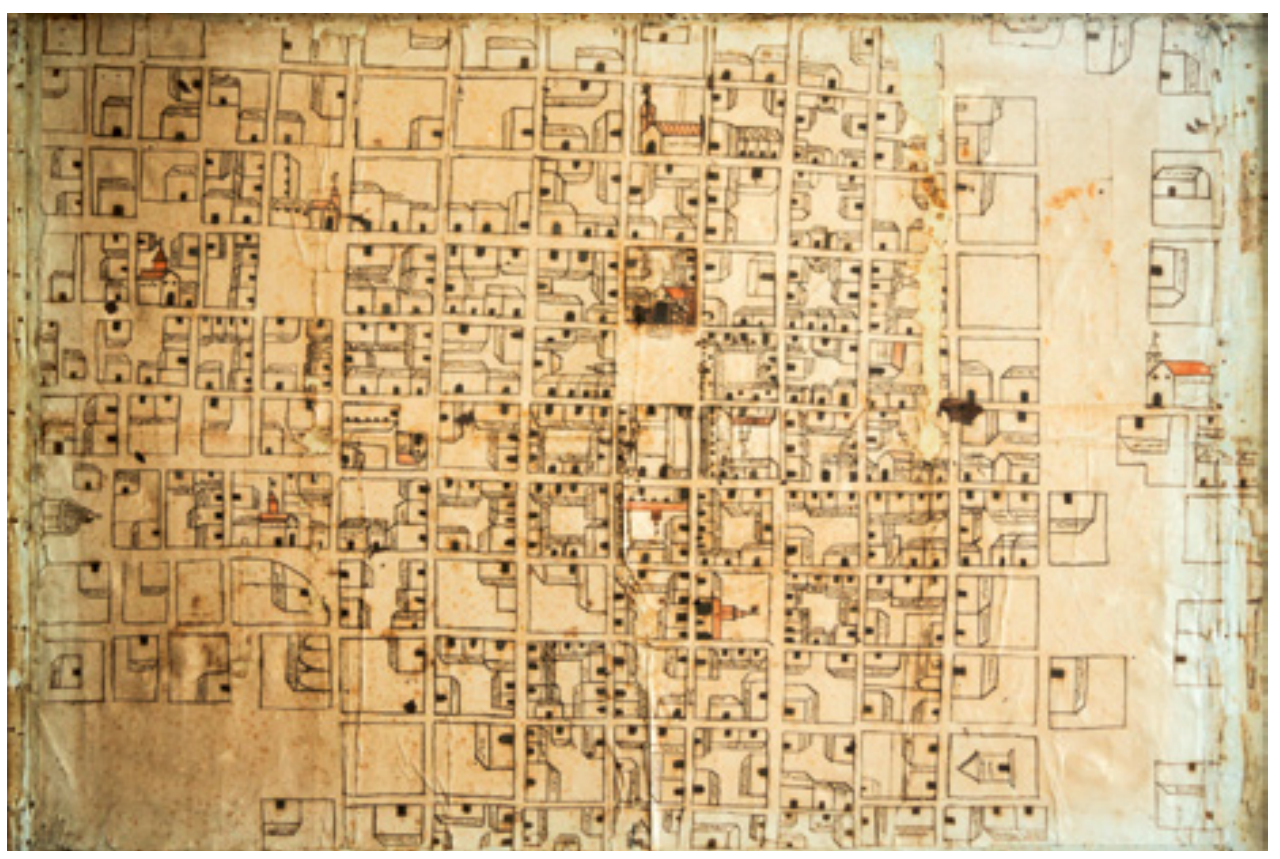

Figura 5. Plano de Tunja, 1623.

Fuente: fotografia de S. Arboleda, 2016.

${ }^{11}$ Se basa en varias fuentes: la descripción de Tunja y su tierra hecha por la justicia de la ciudad en 1610; Los fundadores de Bogotá, de Raimundo de Rivas (1938); Escudos de armas e inscripciones antiguas de la ciudad de Tunja (Rojas, 1939); el plano de distribución de feligresías de 1623, y los planos de la ciudad de 1919 y 1937, conservados en la Biblioteca del Congreso de Washington.
El 7 de abril de 1623, el Dr. Don Fernando Arias de Ugarte divide el curato de la iglesia de Santiago (Correa, 1944) en las parroquias de Santiago, con 35 cuadras y 198 casas; Las Nieves, con 52 cuadras y 141 casas; y Santa Bárbara, con 43 cuadras y 145 casas. Según el Censo de 1610 del Justicia de Tunja (Cortes Alonso, 1985), hay 3500 pobladores entre españoles, indios y negros, y de acuerdo con la Memoria de los vecinos y moradores de la ciudad en 1620, son 4991 pobladores entre españoles, indios y castas (Wiesner, 2008).

En la historiografía de la ciudad se cuenta con un temprano ensayo en historia urbana colonial, realizado por Cortes Alonso (1985). En este, los instrumentos de dominio ideológico de los poderes eclesiástico, encomendero y mercantil son representados en una cartografía social basada en la descripción de Tunja, los nombres de sus fundadores y escudos de armas, con sus implicaciones dialécticas y repercusiones espaciales en la construcción física. Se concluye que la ciudad del siglo XVI es similar a la del XX en cuanto a trazado y composición socioespacial.

El ensayo de Cortes Alonso ${ }^{11}$, al sobreponer la cartografía social con la geográfica, relaciona la composición social de los vecinos, la iconografía colonial de los poderes político y religioso, la estructura espacial y el sistema económico para probar la

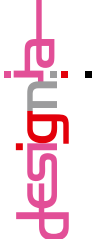


diferenciación y la clasificación espacial, producto de jerarquías sociales basadas en la raza y las preeminencias sociales, en la parroquia de Santiago como fundación original y en el primer ensanche formado por las parroquias de Santa Bárbara y Las Nieves. Este hecho social clasificatorio es perpetuado por la cultura sobre la urbe modernizada del siglo XX, donde se refleja una "división social del espacio".

Hacia mediados del siglo XVIII la populosa ciudad del Nuevo Reino de Granada es despoblada por causa de la peste, además, el barrancoso terreno disminuye a 100 la cantidad de cuadras (Rubio \& Briceño, 1909). Después, Tunja hierve a fuego vivo con las guerras de independencia y las guerras civiles del proceso de formación y consolidación del Estado Nación entre 1810 y 1830, lo cual merma aun más el número de pobladores. De esto da cuenta el político y periodista Manuel Ancízar (1856) en su visita a la provincia a mediados del siglo XIX, al manifestar que la ciudad solo alberga cerca de 5000 habitantes.

Si se toma por cierto el conteo de Wiesner (2008) de 4991 pobladores; la mengua de habitantes por la peste y la disminución a 100 del número de cuadras debido al barrancoso terreno en el siglo XVIII; la diezma generada por las guerras de independencia entre 1810 y 1819; y el cálculo de Ancízar de casi 5000 personas en 1850, se infiere que la población de Tunja no cambia porque el crecimiento vegetativo y la inmigración fuesen proporcionales con los fallecimientos por epidemia o guerra. Hay una tendencia a ocupar menor número de cuadras durante dos siglos, mientras que la propiedad se fracciona sobre la misma superficie. 
${ }^{12} \mathrm{Su}$ título, enmarcado en cartela y motivos vegetales y geométricos, es: "Plano de la Ciudad de Tunja situada a $5^{\circ} 32^{\prime} 12^{\prime \prime}$ de latitud boreal, por Alejandro Vélez, en

Santa Fe, año de 1816". Está montado sobre tela de $37^{\prime} 2$ por 53'8 (94,5 x 132,65 cm).

Aparece lavado en gris, verde y azul, con escala numérica doble en 300 toesas y 800 varas castellanas. Muestra vegetación, topografía en barrancos, cárcavas y ríos. La línea meridiana presenta una Flor de Liz invertida. Contiene una "explicación" de 21 sitios de interés enumerados, cuya transcripción es: 1. Matriz; 2. Fuente; 3. Casa del Govierno; 4. Cabildo; 5. S. Juan de Dios; 6. Sto Domingo; 7. Antiguo Hospital; 8. Sta Bárbara; 9. El Topo, recolecion de Candelarios; 10. La Consepción; 11. S Lauriano; 12. Sta Clara; 13. S Agustín; 14. Fábrica de Nitros; 15. Las Niebes; 16. S. Fransisco; 17. Sta Lucia; 18. La Fuente grande; 19. Loma de los Ahorcados; 20. Chiquinquira; 21. Rio de los Gallinazos. El plano se encuentra disponible en http://www.banrepcultural. org/sites/default/files/lablaa/ geografia/carboy/17.pdf.

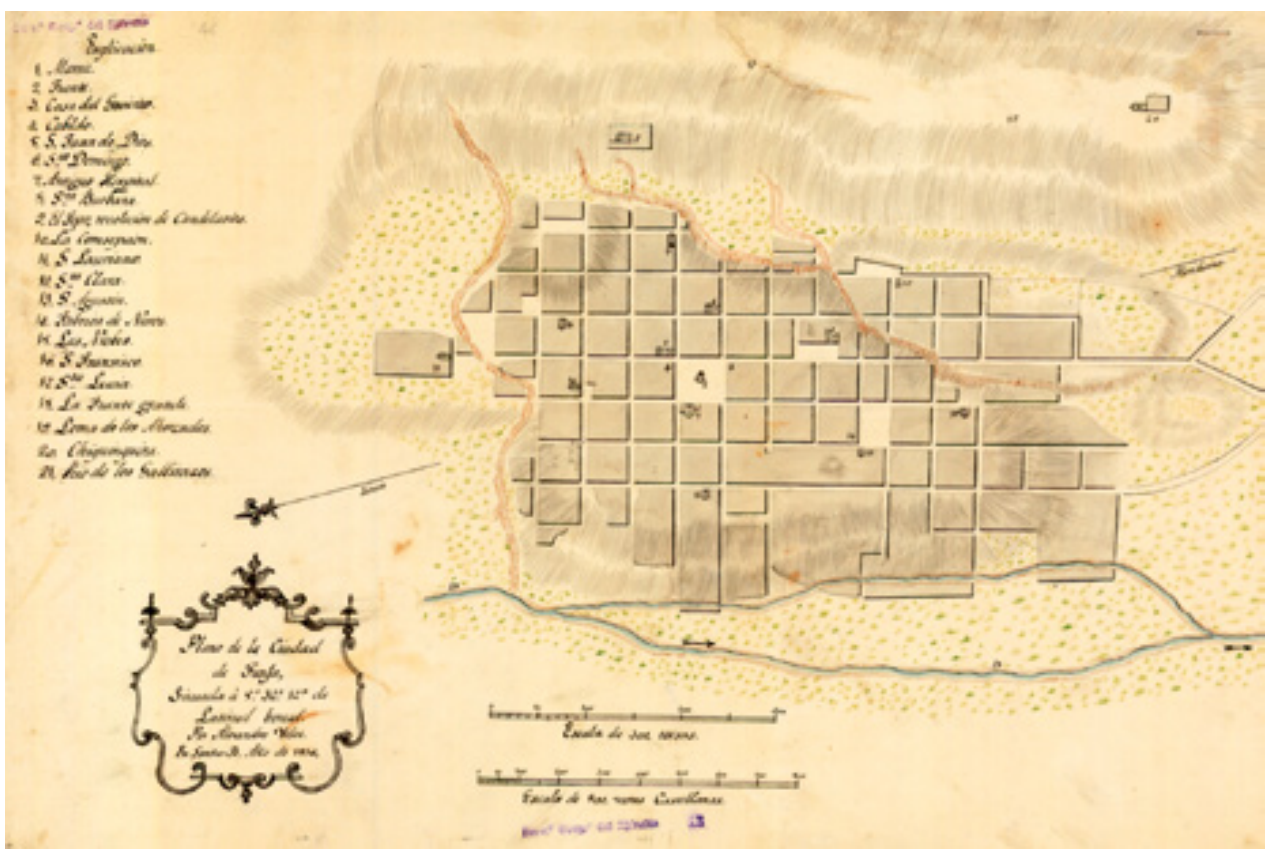

Figura 6. Plano de Tunja, 1816. Fuente: Banco de la República (2003).

De ello da cuenta el plano del siglo XIX, conservado por el Archivo Cartográfico y de Estudios Geográficos del Centro Geográfico del Ejército de Madrid ${ }^{12}$. 
El plano de 1623 muestra 130 cuadras mientras que en el de 1816 se aprecian 90 y no 100 como afirman Rubio y Briceño (1909). Las demás limitan con cárcavas y se refunden al occidente sobre las zonas de influencia de San Laureano, El Topo, Santa Lucía y la Loma de los Ahorcados. Se observa una reacomodación de fuentes de agua y la apertura de plazuelas en las iglesias de Santa Bárbara y La Concepción. En San Francisco hay una plazuela y una calle desplazada; en San Agustín un englobe de cuadras, y al occidente, la iglesia de El Topo y Chiquinquirá.

La ciudad presenta edificios sin aleros, calles empedradas sin andenes, el atrio en la iglesia mayor es de poca anchura, las tiendas de la plaza central y la Calle Real tienen puertas forradas en cuero o lata, hay cuatro plazas (San Laureano, San Juan de Dios, San Francisco y Suárez Rendón), las fuentes públicas para abastecimiento de agua son Abreú o Abreo, Santa Bárbara y las situadas en la esquina occidental en la calle de la Gendarmería, la esquina sur de San Francisco, la plazuela de la Penitenciaría y junto al convento de Santa Clara. El agua no escasea, hasta que por ornato público se suprimen las cajas de Tras del Alto, de modo que Santa Bárbara y Abreo quedan en la calle siguiente a los solares del hospital de caridad. Las personas acomodadas se proveen de agua de la fuente grande, y los pobres, del agua rezada de la Pila Salada (Rubio \& Briceño, 1909).

Desde lo simbólico del culto católico, el urbanismo en la Colonia en Hispanoamérica inserta los mismos propósitos que animan al arte y la arquitectura. El tiempo y el espacio ordinario de la ciudad profana se transforman en otros de tipo litúrgico en la ciudad sagrada durante las celebraciones del día de fundación, la semana mayor, el jueves de Corpus Christi y la Inmaculada Concepción. En estas ocasiones la gente desborda los templos y se vuelca a las calles, transformándolas en vías sacras por donde transitan espectaculares procesiones (Salcedo Salcedo, 1996).

Se conforma una estructura de espacios abiertos espectaculares (plazas, plazuelas, calles y balcones) y de espacios cerrados en iglesias, ermitas y conventos, los cuales participan de "ver o de ser visto", de modo complementario o suplementario. Los templos con plaza o plazuela forman unidades complementarias que, a su vez, se articulan y comunican a otras unidades merced de calles reales, para constituir así unidades suplementarias y establecer estructuras formadas por unidades de reposo o detención y movimiento o flujo de creyentes fieles, "leales vasallos". Un sistema de posas y flujos en una ciudad procesional (Porras Collantes, 2006). 
El sistema procesional vincula espacios de espectacularidad arquitectónica, entre los cuales se encuentran casas altas o bajas que participan con arrogancia o modestia del espectáculo frente a las vías sacras. Sus elementos constructivos y decorativos relacionan el espacio interior con el exterior a traves de la forma y el número de vanos en portadas y ventanales, balcones, volados o corridos. Algunos funcionan como atalayas preeminentes y privilegiadas, muy apetecidas para observar espectáculos reales, procesiones religiosas, danzas y fiestas de toros en la plaza mayor, con balcones generosos para quienes miran y son mirados.

La espectacularidad procesional vincula los símbolos exhibidos en los escudos de armas labrados sobre las portadas de viejas mansiones señoriales, los escudos episcopales o eclesiásticos labrados en las portadas de conventos e iglesias, y las inscripciones antiguas al interior de los templos situados en capillas y sepulcros. El blasón es la piedra fundamental, el símbolo más preciado de preeminencia social, patronato, jerarquía y nobleza entre caballeros, escuderos e hidalgos de menor fortuna y rango en relación con la nobleza de sangre, el cual, en ciudades como Tunja, se otorga por real cédula de la Corona (Rojas, 1939).

Las casonas de fundadores y vecinos preeminentes son hechas con fábrica costosa, portadas y escudo de armas labrado para eternizar su fama, vanidad, linaje caballeresco, hidalgo o señorial. Orgullo del privilegio y la nobleza lograda por sus servicios, son de dos pisos tipo castellano, con muros en tapia de tierra, cantería en esquinas y portada, patio en claustro a dos o tres frentes, arcos con alfices mudéjares en las galerías bajas y dinteles en las altas al gusto toledano, y escalera en ángulo del patio con cubierta en teja de barro, para orgullo civil (Dorta, 1942). 
En las iglesias, los signos exteriores en fachada principal, naves, cubiertas, cúpulas, torre, campanario y espadaña, se relacionan con obras interiores de carpintería en retablos, púlpitos, confesionarios, tabernáculos, ventanas, puertas, artesonados de techumbre, ornamentos, muebles, pinturas, imágenes, cofres, custodias y copones, para conformar así el universo simbólico del Gótico Mudéjar renacentista. Los trabajos son realizados por vecinos y corporaciones, ya sea por accion social o por dominación ideológica de la iglesia.

El sistema de signos y símbolos exteriores que destaca por encima del tejado de viejas mansiones, visible en cúpulas, torres, campanarios, espadañas y frontones, se integra al preciosismo interior de conjuntos decorativos revestidos con madera tallada y policromada en muros, arcos y bajo cubiertas con aplicaciones doradas y fondo rojo. El barroco y la decoración renacentista o plateresca se representan en motivos vegetales o animales, animados por sentimientos cristianos y autóctonos.

\section{CONCLUSIONES}

La reflexión en torno a los fundamentos del urbanismo colonial en Tunja evidencia cuatro aspectos esenciales del periodo de implantación del modelo ideológico metropolitano español que contiene el germen de la idea de colonialidad como poder unidireccional capaz de someter cualquier otro proyecto vital. El primer aspecto es el trazo en cuadrícula como espacio pedagógico; el segundo, el sueño de orden para vivir en policía; el tercero, la división social del espacio en la ciudad; y el cuarto, la espectacularidad procesional como instrumento de dominio colonial.

La cuadrícula con centro en una plaza como espacio pedagógico, de celebración y convergencia comunitaria cotidiana tiene funciones políticas, sociales y económicas del mercantilismo español, al igual que misionales del catolicismo. Estas se orientan a convertir los indígenas infieles a la religión y ayudar en su salvación mediante la impartición de sacramentos como acción civilizadora, para su adoctrinamiento, modelación y dominación ideológica en el amor a Dios y al monarca. 
El sueño de orden al vivir en policía define la vida urbana y la política como buen gobierno y justicia, cortesía en el trato y las costumbres, aseo, belleza y pulidez, todas virtudes necesarias para la fe cristiana. Forma urbana, comportamientos y moral son prácticas de regulación e imposición del orden, orientadas a erradicar las creencias y prácticas de idolatría entre los indígenas, contrarias a la idea de gracia. Según esta idea, Dios capacita al hombre para ejecutar su voluntad en la tierra en una estructura de ciudad abierta que congrega a la comunidad alrededor del centro.

La división social del espacio en la ciudad se ilustra por la distribución de feligresías en las parroquias de Tunja, como se aprecia en el plano de 1623. Se representa así una cartografía social según la posición social de los vecinos, prueba fehaciente de una clasificación espacial producto de jerarquías basadas en la raza y las preeminencias sociales. En la parroquia de Santiago se asienta un grupo superior y preeminente de raza blanca, mientras que en las parroquias de Santa Bárbara y Las Nieves, un grupo inferior de mestizos, indios o pardos de todos los colores.

En el espectáculo procesional como instrumento de dominio colonial, el tiempo y el espacio ordinarios de la ciudad profana se transforman en otros de tipo litúrgico en la ciudad sagrada durante las celebraciones religiosas. El sistema procesional vincula espacios urbanísticos abiertos con aquellos arquitectónicos cerrados sobre las vías sacras para exhibir símbolos de preeminencia real, eclesiástica o civil que eternizan el privilegio, la fama, nobleza y vanidad de monarcas, hidalgos y el clero. 


\section{REFERENCIAS BIBLIOGRÁFICAS}

Ancizar, M. (1856). Peregrinación de Alpha: Por las provincias del norte de la Nueva Granada, en 1850-1851. Bogotá: Biblioteca de la presidencia de la Colombia. Disponible en www.bdigital.unal.edu.co/3/ .

Arboleda, S. (28 de 04 de 2016). Fotografia del plano de la ciudad de Tunja de 1623. (Universidad de Boyacá, Ed.) Tunja.

Beltrán de Heredia, S. V. (1982). Un modelo teórico de ciudad en el siglo XVI: la ciudad de Eximenis. Madrid: Universidad Complutence de Madrid / Marcual Ponds Librero.

Bonet Correa, A. (1991). El urbanismo en España e Hispanoamérica. Madrid: Cátedra.

Brewer Carías, A. R. (1998). Poblamiento y orden urbano en la conquista española de América. Madrid: En: Jornadas Internacionales sobre Derecho Urbanístico, Universidad de Santiago de Compostela.

Colmenares, G. (1970). La provincia de Tunja en el Nuevo Reino de Granada. Ensayo de historia social (1539-1800). Tunja: Academia Boyacense de Historia.

Cortes Alonso, V. (1985). Tunja y sus vecinos. Repertorio Boyacense n. 317, 1-55.

Dorta, M. E. (1942). La arquitectura del renacimiento en Tunja. Madrid: Tirada aparte del $N^{\circ} 9$ de la Revista de Indias.

Londoño, E. (1992). Guerras y fronteras. Los límites territoriales del dominio prehispánico de Tunja. Boletín Museo de Oro(32-33). Banco de la República. Recuperado el 28 de 2 de 2015, de http://www.banrepcultural.org/blaavirtual/publicacionesbanrep/bolmuseo/1992/endi3233/endi01e.htm

Mateús Cortes, G. (2006). Fotografía del Plano de feligresías parroquiales de 1623 ubicada en el Palacio Arzobispal de Tunja. En E. Porras Collantes, Corónica colonial de Tunja y su provinica (pág. Sp). Tunja: Academia Boyacense de Historia y Fondo Mixto de Cultura.

Mejía Pavony, G. R. (2000). Los años del cambio. Historia urbana de Bogotá 1820-1910. Bogotá DC: Consejo Editorial Javeriano CEJA, $2^{\circ}$ Edición, pág. 498.

Morse, R. (1975). Introducción a la historia urbana de Hispanoamérica. Madrid: Consejo Superior de Investigaciones Científicas / Instituto Gonzalo Fernández de Oviedo.

Porras Collantes, E. (2006). Corónica colonial de Tunja y su provincia. Tunja: Academia boyacense de historia / Fondo mixto de cultura de Boyacá. 
Rojas Mix, M. (1978). La Plaza Mayor: El urbanísmo, instrumento de dominio colonial. Barcelona: Muchnik Editories.

Rojas, U. (1939). Escudos de armas e inscripciones antiguas de la ciudad de Tunja. Tunja: Junta del IV Centenario.

Romero, J. L. (1999). Latinoamérica: Ciudades y las ideas. Medellín: Medellín, Editorial Universidad de Antioquia.

Rubio Ozías \& Briceño Manuel. (1909). Tunja. Desde su fundación hasta la época presente. Bogotá: Imprenta Eléctrica, pág. 331.

Salcedo Salcedo, J. (1996). Figura 1: Tipos de trazas. En: Urbanismo Hispanoamericano Siglos XVI, XVII y XVIII. El modelo urbano aplicado a la América española, su génesis y su desarrollo teórico y práctico (pág. 43). Santafé de Bogotá: Consejo Editorial Javeriano CEJA.

Salcedo Salcedo, J. (1996). Figura 2: Trazo de Popayán. Urbanismo Hispanoamericano Siglos XVI, XVII y XVIII. El modelo urbano aplicado a la América española, su génesis y su desarrollo teórico y práctico (pág. 53). Santafé de Bogotá: Consejo Editorial Javeriano CEJA.

Salcedo Salcedo, J. (1996). Figura 3: Trazas difundidas en el virreinato de Perú. Urbanismo Hispanoamericano Siglos XVI, XVII y XVIII. El modelo urbano aplicado a la América española, su génesis y su desarrollo teórico y práctico (pág. 68). Santafé de Bogotá: Consejo Editorial Javeriano CEJA.

Salcedo Salcedo, J. (1996). Urbanismo Hispanoamericano Siglos XVI, XVII y XVIII. El modelo urbano aplicado a la América española, su génesis y su desarrollo teórico y práctico. Santafé de Bogotá: Consejo Editorial Javeriano. CEJA.

Suárez García, C. J. (2015). El urbanismo humanista y la "policía española” en el Nuevo Reino de Granada, siglo XVI. Topoi. Revista de historia. Rio de Janeiro, v. 16 n. 30, jan./jun., 127-156 Disponible en: www. revistatopoi.org.

Suárez García, C. J. (2015). Figura 4: Plano hipotético del trazado urbano de los pueblos de indios. El urbanismo humanista y la "policía española" en el Nuevo Reino de Granada, siglo XVI (pág. 151). Río de Janeiro: Topoi, Revista de historia, v. 16 n. 30, jan./jun. Disponible en: www.revistatopoi.org.

Velez, A. (1816). Plano 2: Plano de la ciudad de Tunja. Santa Fe. [Escala 1:5300] 800 varas castellanas (págs. Montado sobre tela 37'2 x 53'8 Lavado en gris, verde y azul). Madrid: Archivo Cartográfico y de Estudios Geográficos del Centro Geográfico del Ejército. Obtenido de http://www.banrepcultural. org/sites/default/files/lablaa/geografia/carboy/17.pdf

Wiesner, L. E. (2008). Tunja, ciudad y poder en el siglo XVII. Tunja: Universidad Pedagógica y Tecnológica de Colombia, UPTC. 